\title{
REVISING CURRICULAR ON MEDICAL ETHICS: A WAY FORWARD
}

Paranitharan P. \& Perera W.N.S.

Department of Forensic Medicine, Faculty of Medicine, University of Kelaniya, Sri Lanka

Corresponding Author: Paranitharan P.

Email:paran28@gmail.com

iD https://orcid.org/0000-0002-1913-6085

\begin{abstract}
In this modern era practicing medical ethics has become more demanding. The advancement of science with new technologies, new therapies and complex clinical trials has resulted in a situation where the current principles and concepts of medical ethics alone are not adequate in situations. Therefore, teaching ethics to medical students in a broader way as medical bioethics would cover the implications that result following treatment or research and is more beneficial for patients or participants. This paper illustrates the need of transforming the teaching of medical ethics to medical bio ethics as a way forward.
\end{abstract}

Keywords: Medical ethics, Medical bio ethics, practice, transformation

All articles in Sri Lanka Journal of Forensic Medicine, Science \& Law are licensed under the terms of the licensed under a Creative Commons Attribution-Non Commercial 4.0 International License. 


\section{INTRODUCTION}

Medical ethics is a collection of moral principles that applies values and better judgment to the actions taken in the practice of medicine ${ }^{1}$. Medical ethics in the Hippocratic era had recognized values such as confidentiality, impartiality and do no harm which are still valid in present context ${ }^{2}$. After world war two there was rapid advance in medical research, new approaches in treatment and introduction of new medical devices ${ }^{3}$. In such situations the Nuremburg code, Belmont principles and Declaration of Helsinki etc. have provided useful guidelines to safe guard patients' rights and doctors' values. However, in some critical situations where decision making is vital these principles conflict with each other ${ }^{4}$. On the other hand, those principles provide indirect immunity to the treating doctor from allegations of medical negligence $^{5}$ and preserves the rights of patients ${ }^{6}$.

During the last few decades medical and biotechnological fields have expanded extensively. Traditional moral values of the physicians are challenged in various situations of decision making and patient management ${ }^{7}$. With the health care inequalities specially in limited resource settings and emergence of new methodologies such as high-risk therapeutic measures, in-vitro fertilization, complex medical devices and genetic and embryonic research, traditional medical ethics have become inadequate and cannot totally be relied upon to assist physicians ${ }^{8}$.

Further these situations may warrant immediate action with inadequate time for ethical evaluation. In such instances, especially the vulnerable populations are at risk. The twenty first century demands more advanced ethical norms to face new developments in science and technology. Therefore, understanding and application of bio ethics plays an important role in medicine.
The objective of this paper is to discuss the necessity of widening the scope of medical ethics into bio medical ethics in medical fields with the view of teaching it to the professionals and personnel who are involved in caring for patients.

\section{DISCUSSION}

The main ethical principles described in Belmont principles are namely respect for persons, beneficence, and justice ${ }^{9,10}$. Even with its' limitations those principles helped the clinicians to take decisions in conflicts situations, research with human subjects accordingly and mostly limited to applied ethics. Within last few decades' complexity of ethical dilemmas faced by doctors in the ward has rapidly increased and became more complex due to advances in medicine ${ }^{11}$. The values of individuals including doctors are challenged frequently due to reasons, such as changes of social norms and values, prioritisation of materialistic aspects associated with technological and economic development, political influence and social media. Therefore, learning medical ethics not only assists doctors in managing ethical dilemmas but also helps in defining personal values.

Bio ethics does not have a single definition but encompasses a broader spectrum which is used to explain the application of moral principles to biomedical aspects considering humans nature ${ }^{12}$. The notion of bio ethics was first introduced by Potter in 1970 describing it as humanistic ethics resulting from biology and medicine ${ }^{13}$. Within months Helleger and Sargent Shriver independently stated that ethical scrutiny of precise problems raised by medicine and the biological sciences by professionals as bio ethics $^{14}$. In 2010 Dawson represented it as "all ethical issues rising from the creation and maintenance of the health of living

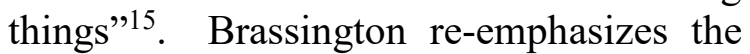
purpose of bioethics as being "to produce action-guiding advice to given concerns for 
morality"16. In these explanations scope of bio ethics is much broader than the medical ethics.

Medical ethics has been expanded in universal declaration on bioethics and human rights in $2005^{17,18}$ generating new bio ethical principles recognized by UNESCO and incorporating rights of the human and animal, environment, life sciences and progress in technology. It recognizes elements which were not directly spelled out in Belmont principles. Attributes such as human dignity and freedom over the science, non-discrimination and nonstigmatization, regards on cultural diversity and pluralism are among them. Further UNESCO recognizes solidarity among human and international cooperation, promotion of health and social development as a responsibility of all sectors and importance of sharing benefits of scientific research. It gives due repute on future generations and genetic constitution, protection of environment, biosphere and bio diversity. Compulsorily these aspects of bio ethics offer multi sectoral approach in development of health, taking responsibility, involvement and collaboration in resolving health related conflicts and better future out comes in providing health facilities while upholding ethical norms ${ }^{19}$.

Recognition and application of these bio ethics principles is more relevant to us in the present-day, since Sri Lanka is part of bio bank research, genetic studies, drugs and vaccine multi-center clinical trials. Ethical aspects related to handling of biological samples, disposal of clinical waste and handling of human subjects in complex research trials are few examples where the application of bio-ethics would be needed. In addition, every day health care activities of medical personnel are challenged in diverse aspects while intertwined with media. As an answer to those challenges' bio ethics has allowed scrutiny of healthrelated activities by non-medical personnel such as lawyers, philosophers and lay people. Multi sectorial approaches strengthen accountability, transparency and feeling of professionals for legitimacy of their activities ${ }^{20}$. This aspect is practiced in recognized ethics review committees in Sri Lanka, which include members from multiple disciplines. Non-medical participants look into the matters from the lay persons angle and represents public interest in those committees.

Bio ethics is not merely a subject dealing with life sciences but also consider future outcomes of action in an ethical angle and move forward with other humanistic disciplines. ${ }^{16}$ Contribution from many fields take the responsibility not only to resolve conflict situations but to strengthen the right outcome at the end ${ }^{21,22}$. Therefore other fields such as law, science and philosophy recast the medical ethics generating better solutions in the field ${ }^{23}$. It provides present and future frame work for physical as well as moral advances in medicine. It has connections with application ethics and philosophy in a cultural dimension ${ }^{24}$. Bio ethics demands not only ethical approach but also novel solutions to existing problems such as inadequacy of resources, ecological disasters, rights of under-privileged, political and economic disadvantages on health issues ${ }^{25}$. Therefore, medical ethics which are taught as an indispensable part of the medical curricula as a module or strand and its teaching methods such as lectures and tutorials which give basic knowledge on ethical principles and its application are not sufficient to cater to the needs of the day and future and need transformations ${ }^{26}$.

Present day teaching of medical ethics should be emphasized and expanded into bio ethics, be included in different subjects from the beginning of medical education and should be reinforced with clinical exposure $^{17}$. Then only the teaching process will help the learners to convert the assembled knowledge into practice ${ }^{18}$. 


\section{A. Present day situation of teaching medical ethics}

A student who has had 13 years of school education in diverse social and cultural backgrounds needs to be transformed into a practitioner, scientist and to a professional after 5 years of medical education in Sri Lanka. To accomplish these out comes they should develop basic knowledge in medical science, clinical and patient management skills, communication skills, interpersonal skills, professional values and attitudes. Today medical ethics is taught in Sri Lankan medical schools with inclusion of topics such as basic ethical principles, consent, confidentiality, medical negligence, medical council and professional misconduct. Professionalism is discussed in some medical faculties. Most topics are delivered as lectures or tutorials while some faculties use case-based scenarios in small group discussions. With the clinical exposure students learn ethics from role models. However, it appears that the expected behavioural change following 'taught ethics' is not adequate at the time of starting their career as a doctor and thereafter ${ }^{27}$. There have been several reported instances where concerns were raised by the public and media in relation to the doctor-patient relationship, acts of medical negligence and violation of rights of patients. The present medical curricula can be transformed to incorporate a multi-disciplinary ethical approach to conflict resolution with problem solving and policy making in health, citing the new trends in bioethics.

\section{B. Integrating bio ethics into medical teaching}

UNESCO bio ethics curriculum ${ }^{28}$ can be used as a guide with adaptations to suite the socio- cultural dimensions of the country. Different facets of bio ethics can be brought to the notice of the pre-clinical students before clinical exposure specially using films and television series with ethical dilemmas building on their gut feeling and on moral values. Discussions can be initiated during preclinical teaching on their perceptions on ethical issues even without a theoretical background. It will help them to mould into a socially responsible, accountable person with humanistic values and empathy towards the patient even prior to clinical learning.

Traditional methods of teaching are not adequate in bio ethics ${ }^{17}$. During para clinical years' small group discussions on ethical issues, case-based seminars and dramas, reflective writing on ethical issues experienced during clinical attachments help students to identify, asses and arrive at a conclusion on how to act in case of an ethical dilemma ${ }^{29}$. Focused issues such as consent taking, confidentiality of information can be taught using audio and video clips and role plays. Culturally and socially appropriate concerns can be assimilated to the case discussions giving more relevance with panel discussions to clear doubts. There should be a common virtual platform where teachers can share the learning material with other university teachers and students across the country. It will provide a solution to the lack of socioculturally relevant learning material on bio ethics. A more practical elective module can be offered for students who are interested in broadening their knowledge and application in bio ethics.

Further, gathered knowledge and skills of a medical student on ethics should be strengthened every day in the ward setting. Bed side teaching of bio ethics in each discipline gives holistic attitude to the problems where the learner can interact with the patient while learning emotional, social and cultural attributes of ethics ${ }^{30}$. Continuous professional development programmes for academics and clinicians have to be strengthened by providing training with the aim of integrating ethics teaching routinely at the bed side. This is essential because unlike in any other discipline role models and the hidden 
curriculum plays an important part in learning ethics ${ }^{31}$. More advanced concepts can be discussed highlighting intrinsic ethical issues during post graduate training relevant to each field. Universities should be given the task of developing short modules on bioethics and making it a mandatory short appointment, will be the answer to build knowledge, attitudes and practices of future doctors. However, converting the knowledge into a practice in the real world is determined by several factors and more difficult to accomplish. Adequate and suitable continuous assessment of bio ethics is mandatory to achieve the objectives of learning. Using video and audio clips and simulated patients with communication stations increase the validity of practical assessment.

A strong bio ethics curriculum not only prepares a medical student and post graduate student for future practice as a professional but also teaches on how to reflect on their own views and potential biases in health management. Further it gives an opportunity to interact with other fields and recognizes the expectations of patients and public ${ }^{27}$.

\section{B. Integration of bio ethics into other health related fields}

Health care is team work and there are several other disciplines and personnel that closely work with physicians in patient management. Administrators who make public policies on health, paramedical personnel, therapists, nurses, social workers, scientists and hospital minor staff are involved in various situations of patient management and care. Bio ethics has its wider use in such situations addressing ethical aspects in many fields related to human rights, life sciences, environment and technology, making it more applicable to them. Therefore, the time is ripe to address the necessity of introducing concepts of bio ethics and relevant applications in learning curricula of fields allied to medicine and health.

\section{CONCLUSION}

Medical ethics is based on moral values that helps in making judgments and decisions in the practice of Medicine. Whereas bioethics encompasses a broader spectrum which is used to explain the application of moral principles to biomedical aspects of humans and nature. Learning bio ethics in comparison to medical ethics helps medical personnel improve their professional ethics by developing critical thinking, allowing application in ethical dilemmas and guidance to consider implications of health polices to society and patients. In an era where public demand on executive bodies and administration, who implement health related decisions are increasing, bio ethics is more relevant than medical ethics. Therefore, introducing bio ethics into medical fields replacing applied medical ethics is a need of the day. 


\section{REFERENCES}

1. Beauchamp TL, Childress JF. Principles of Biomedical Ethics. Fifth edition. Oxford University Press; 2001.

2. Antoniou SA, Antoniou GA, Granderath FA, Mavroforou A, Giannoukas AD, Antoniou AI. Reflections of the Hippocratic Oath in modern medicine. World Journal of Surgery. 2010 Dec;34(12):3075-9. doi: $10.1007 / \mathrm{s} 00268-010-0604-3$

3. Kuroyanagi T. Historical Transition in Medical Ethics- Challenges of the World Medical Association. Japan Medical Association Journal. 2013;56(4):220-226

4. Limentani AE. The role of ethical principles in health care and the implications for ethical codes. Journal of Medical Ethics. 1999;25:394-398

5. Bevinahalli N, Raveesh, Ragavendra B, Nayak et al. Preventing medico-legal issues in clinical practice. Annals of Indian Academy of Neurology. 2016 Oct; 19(1): S15-S20 doi: 10.4103/0972-2327.192886

6. Riddick FA. The Code of Medical Ethics of the American Medical Association. Ochsner J. 2003 Spring; 5(2): 6-10

7. MacKenzie RC, What Would a Good Doctor Do? Reflections on the Ethics of Medicine. HSS J. 2009 Sep; 5(2): 196-199 doi: 10.1007/s11420-009-9126-7

8. Wilson D. Creating the 'ethics industry': Mary Warnock, in vitro fertilization and the history of bioethics in Britain. Bio societies. 2011 Jun; 6(2): 121-141.

9. Beauchamp T. History and theory in "applied ethics". Kennedy Institute of Ethics Journal. 2007;17:55-64

10. Department of Health and Human Services. History of the Belmont Report and the federal regulations [Internet]. 2008 [cited 2009 July 2]. Available from: http://www.hhs.gov/ohrp/belmontArchive. html\#histReport
11. Global health Ethics key issues, Global network of WHO collaborating Centres for bio ethics WHO. 2015. Available from: www.who.int

12. Chan S, Coggon J. Beyond the Is/Ought divide: Studying the nature of the Bioethical enterprise Health Care anal. 2013;21:1-5

13. Potter VR. Bioethics: The Science of Survival. Perspectives in Biology and Medicine. 1970;14(2):127-153.

14. Wilson D. The Making of British Bioethics, Manchester (UK): Manchester University Press; 2014

15. Dawson A. The future of bioethics: three dogmas and a cup of hemlock. Bioethics. 2010 Jun;24(5):218-25

16. Brassington I. What's the point of philosophical bioethics?. Health Care Anal. 2013;21(1):20-30.

17. Bio ethics education UNESCO chair's methodology, what to teach and how to teach, Amnon Carmi, UNESCO

18. Downie R, Clarkeburn H. Approaches to the teaching of bioethics and professional ethics in undergraduate courses, bioscience education.5:1-19

DOI:10.3108/beeg.2005.05000003

19. Chadwick R, Wilson D. The Emergence and Development of Bioethics in the UK. Medical Law Review. 2018 May; 26(2): 183-201

20. Wilson D. Creating the 'ethics industry': Mary Warnock, in vitro fertilization and the history of bioethics in Britain. Bio societies. 2011 Jun; 6(2): 121-141

21. Thiele F. International Encyclopaedia of the Social \& Behavioural Sciences. $2^{\text {nd }}$ ed. 2015

22. Stempsey WE, in Encyclopaedia of Applied Ethics. $2^{\text {nd }}$ ed. 2012

23. Robert MV. How Philosophy of Medicine Has Changed Medical Ethics. Journal of Medicine and Philosophy. 2006;31(6) 
24. Morgan A. American Medical ethics revolution, Professionalism and professional ethics, 184

25. Onora O'Neill. Autonomy and Trust in Bioethics, Cambridge University Press. 2002

26. Carrese, Joseph A, Malek, Janet et al. The Essential Role of Medical Ethics Education in Achieving Professionalism, The Romanell Report. Academic Medicine. 2015 June;90(6):744-752 doi: 10.1097/ACM.0000000000000715

27. Saltzburg L. Is the current state of medical ethics education having an impact on medical students?. Online Journal of Health Ethics [Internet]. $2014 ; 10(2)$. Available from:

http://dx.doi.org/10.18785/ojhe.1002.02
28. Bioethics Core Curriculum - Section 1: syllabus ethics education programme, UNESCO Publication. Available from:http://www.unesco-chairbioethics.org/?mbt_book=bioethics-corecurriculum

29. Shereen A, Tarhouny El. Teaching bioethics for undergraduate medical students. Biomedical Research. 2017;28(22)

30. Mills S, Bryden DC. A practical approach to teaching medical ethics. Journal of Medical Ethics. 2010 Jan;36(1):50-54

31. Hafferty FW, Frank R. The hidden curriculum, ethics teaching, and the structure of medical education. Aca med. 1994;69:861-871 